\title{
Bovine Ephemeral Fever: Pathological and Immunohistochemical Studies
}

\author{
K. A. El-Nesr*, E. A. Mahdy, M. B. El-Begaway \\ Department of Pathology, Faculty of Veterinary Medicine, Beni Suef University, Beni-Suef 62511, \\ Egypt
}

\begin{abstract}
A natural outbreak of Bovine Ephemeral Fever in Egypt during the summer of 2006 had been observed. In Beni Suef province, out of 70 cattle naturally infected with bovine ephemeral fever virus, three fattening calves suffered from subcutaneous emphysema died and were subjected to post-mortem examination. The findings revealed severe subcutaneous emphysema, interstitial and pulmonary emphysema. The serous membranes were thick, opaque and emphysematous. Microscopically, interstitial and pulmonary emphysema was prominent in most lobes of the examined lungs accompanied with pulmonary oedema and focal leucocytic aggregations in some areas. Angiopathy was demonstrated in all cases. The bronchial and mediastinal lymph nodes showed congestion and hemorrhages. Immunohistochemically, specific reaction for Bovine Ephemeral Fever virus was demonstrated in the lung and lymph nodes of the three cases; the pathogenesis of the disease was discussed.
\end{abstract}

Bovine ephemeral fever virus is an arthropode-born Rhabdovirus belonging to Rhabdoviridae family (Murphy et al., 1972). Bovine ephemeral fever outbreaks occurred in Egypt during the summer of 2000 and 2002 (Sayed et al., 2001; Abd El-Ghaffar et al., 2002). The disease prevalence was high among dairy cattle with low mortality rate (Yeruham et al., 2000). Pathologically, serofibrinous polysynovitis, arthritis, cellulitis with patchy oedema in the lung and lymphadenitis were the most common pathological alterations seen in animals infected with bovine ephemeral fever (OIE, 2005). Pneumonia with pulmonary emphysema and subcutaneous emphysema were also noticed in animals infected with ephemeral fever (Theodoridis and Coatzer, 1979; Sayed et al., 2001; Abd El-Ghaffar et al., 2002). The pathological alterations produced by bovine ephemeral fever virus in the musculoskeletal tissue were fully described (Theodoridis and Coatzer, 1979). The virus could be detected in the blood by fluorescence and PCR (Young and Spradbrow, 1977; Stram et al., 2005).

The aim of the present was to study the pathological alterations associated with bovine ephemeral fever in the internal organs, subcutaneous tissue and skeletal muscle, in addition to detection of the virus distribution in different tissues using immunohistochemical technique.

\footnotetext{
* Corresponding author. Tel.: +20 082 2322066;

Fax: +20 0822327982

E-mail address: khneser@bsu.edu.eg

(Khaled A. A. El-Neser)
}

\section{Material and methods}

A total of 70 cattle of different ages clinically diagnosed to be suffering from bovine ephemeral fever in an outbreak occurred in BeniSuef province, Egypt during the summer of 2006. All animals showed manifestations in the form of high temperature $40-41^{\circ} \mathrm{C}$, lameness, marked drop in milk production, nasal and occular discharge with salivation. Three fattened calves had marked subcutaneous emphysema. These cases died and necropsy was performed.

Pathological study. Postmortem examination was carried out for the three dead calves and tissue specimens were collected from the lung, liver, kidneys, spleen, heart, intestine, skeletal muscles, as well as lymph nodes (prescapular, prefemoral, mediastinal, bronchial, and mesenteric lymph nodes).

Tissue specimens were fixed in $10 \%$ formalin solution, dehydrated cleared and embedded in paraffin. Tissue sections of 5-7 microns were prepared and then stained with hematoxylin and eosin according to Bancroft and Stevens (1996).

Imunohistochemical study. Indirect avidinbiotin complex technique (ABC) (Dako Envison kit K4011 from Santa Cruz, sc- 565, USA) was applied to formalin fixed tissue embedded materials, according to Dako Envison Kits. Polyclonal serum antibodies were obtained from Institute of Serum and Vaccines Production, Abassia, Egypt. Negative and positive control cases were involved. 

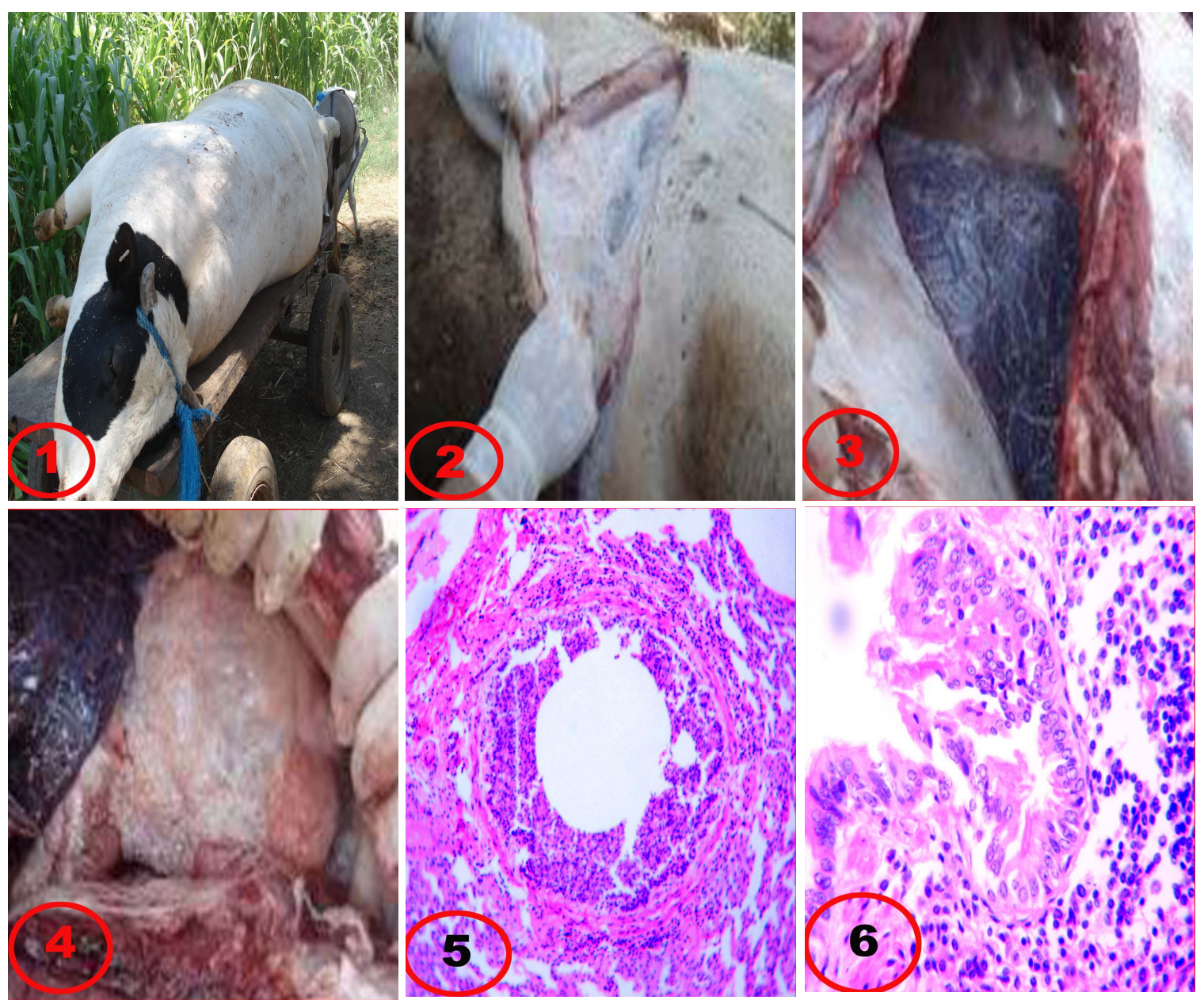

Fig. 1: A dead calf showing severe subcutaneous emphysema involving the whole body.

Fig. 2: Subcutaneous fascia of a dead calf showing emphysema.

Fig. 3: Lung showing interstitial and pulmonary emphysema.

Fig. 4: Thickened, opaque and emphysematous pericardium.

Fig.5: Lung tissue showing cellular debris within bronchiolar lumen (H\&E-X 100)

Fig.6: Lung tissue showing focal leucocytic aggregations adjacent to the bronchi and bronchioles. (H\&E-X 400)

\section{Results}

Gross pathological findings. Severe subcutaneous emphysema was observed, in the three cases, involving the whole body (Fig.1) in two cases and only localized in the shoulder and neck in the third calf. Subcutaneous fascia was emphysematous, thickened and pale (Fig.2). Diffuse hemorrhage was noticed in the pharyngeal area in one animal. Marked pathological changes were observed in the lungs; some lobes were mosaic in appearance, oedematous and cyanosed. Interstitial and pulmonary emphysema (Fig.3) were predominant in some lobes and appeared as small vesicles especially in the subpleura and interlobular septa. On cut section, there were oedema and emphysema separating the lobules. The bronchial and mediastinal lymph nodes were enlarged and congested. Serous membranes (pleura, peritoneum, and pericardium) were thickened, opaque and emphysematous (Fig.4).
The endocardium showed focal congestion. The gall bladder was greatly enlarged. The muscles showed no marked changes. The kidneys showed mild congestion.

\section{Histopathological findings.}

Lung. The epithelium of bronchioles and bronchi revealed mild degeneration with early necrotic changes. Bronchial epithelium was totally destroyed with minimal inflammatory changes. Cellular debris was found inside some bronchioles which led to obliteration of few bronchial lumens (Fig.5). In some areas, the alveolar epithelium was detached with accumulation of the desquamated cells within the alveolar lumen. Focal leucocytic aggregations comprised of macrophages and few neutrophils degeneration of tunica media could also be seen. were observed in some areas especially those neighbouring to some of the bronchi and bronchioles (Fig.6). The peribronchial lymphoid aggregations were occasionally necrosed. 


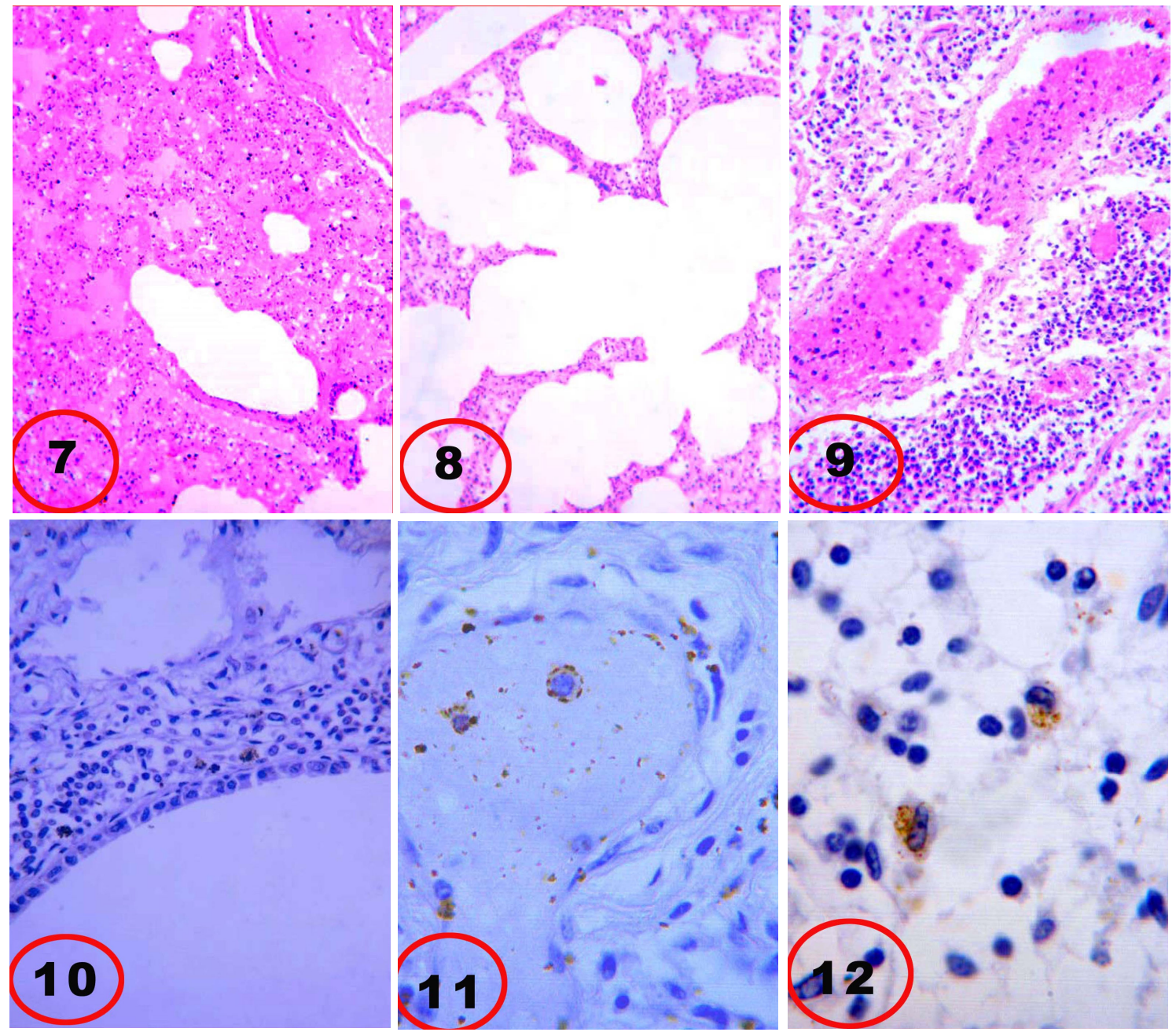

Fig.7: Lung tissue showing completely filled alveoli with proteinaceous fluid (H\&E- X40)

Fig.8: Lung tissue showing interstitial and alveolar emphysema (H\&E- X40).

Fig. 9: Lymph node showing congested blood vessel (H\&E-X100).

Fig. 10: Section of the lung, positive reaction and presence of golden- brown granules in the cytoplasm of mononuclear cells around the bronchial wall (IHC X200 and X400).

Fig. 11: Section of the lung showing positive reaction and presence of golden- brown granules in the cytoplasm of mononuclear cells within blood vessels (IHC X200 and X400).

Fig. 12: Section of bronchial lymph nodes showing positive reaction in macrophages and reticular cells of the lymphoid follicles (IHC, X 1000).

Apoptosis was frequently observed in some alveolar and bronchial epithelial cells. Many alveoli appeared as if being lined by hyalinized membrane. Angiopathy was demonstrated in all cases in which the blood vessels were dilated and congested, some of which showed necrotic changes in the intima and the endothelial cells float within the lumen. Subintimal oedema and In some areas, severe oedematous changes were observed in the interstitial tissue with minimal inflammatory cells. The alveoli were completely filled with proteinaceous fluids in wide areas (Fig.7). The alveoli were markedly overdistended with air and some were ruptured forming interstitial and alveolar emphysema (Fig.8). The adjacent alveoli underwent atelectasis.
Lymph nodes. The lymphoid follicles showed mild hyperplasia with mild degree of necrobiosis in the germinal center of some follicles. Congestion of blood vessels was prevalent (Fig.9). Some areas in the cortex and medulla showed hemorrhage and hemosiderosis. Some of the blood vessels suffered from hyperplasia of intima with thrombus formation. Vasculitis was demonstrated in the medulla. Little of proteinrich odematous fluid was observed in some areas of the stroma. Few neutrophils were found in the paracortex and and around medullary cords.

Kidneys. The epithelial lining of some renal tubules showed mild degenerative changes in the form of vacuolation with pyknosis in a few nuclei. The blood vessels were dilated and congested. 
Intestine. Catarrhal enteritis was noticed with hyperplasia of lymphoid follicles.

Tongue. The dermal blood vessels were congested and some of which had thrombosis.

Skeletal muscles. Some of the muscle fibers were degenerated and necrosed. Oedema was seen in the interstitial area among the muscle bundles.

Liver. Vacuolar degeneration was found in the hepatic cells allover the parenchyma. The central veins and portal blood vessels were dilated and congested.

Heart. Subendocardial and myocardial blood vessels were congested. The myocatdial muscles showed very mild degenerative changes.

Results of immunohistochemical study. A positive immunohistochemical reaction (golden brown granules) for bovine ephemeral fever antigen was demonstrated in the lung and lymph nodes. Specific cytoplasmic and perinuclear reaction was mostly detected in macrophages and reticular cells of the peribroncheal lymphoid aggregates of the lung (Fig. 10,11) and also in lymphoid follicles of the lymph nodes (Fig. 12). The negative control cases showed no immunohistochemical reaction (golden brown granules) for bovine ephemeral fever virus.

\section{Discussion}

Several outbreaks of bovine ephemeral fever (BEF) in cattle have been reported in different localities in Egypt (Sayed et al., 2001; Abd ElGhaffar et al., 2002). Yeruham et al., (2007) reported that in dairy cattle herd, only $12 / 50$ animals were clinically ill with BEF in the dairy community. The lowest morbidity rate was recorded in young heifers $(5.5 \%)$ and the highest was in adult cows (75\%). Only heifers over the age of three months were clinically affected.

Clinically, variable degrees of subcutaneous emphysema were found at the region of the head, neck and back with mild subcutaneous oedema. The mortality rate was $9.76 \%$ in Friezian cattle, $2.19 \%$ in native cattle and $0.0 \%$ in baffuloes (Sayed et al., 2001). Necropsy findings were in the form of subcutaneous and pulmonary emphysema, pulmonary congestion, peticheal haemorrahges on the serous membranes with swelling and redness of skeletal muscles (Theodridis and Coetzer, 1979; Sayed et al., 2001).

In the present study, focal and diffuse subcuatenous and pulomonary emphysema, with lung congestion were the most predominant lesions in the three dead cases. The emphysematous changes were seen in the interlobular and interstitial areas of the lungs. Also, air bubbles extended into the serous membranes especially pleura and pericardium. Pulmonary and subcuatenous emphysema was the most common pathological lesions experimentally produced in the cases of Bovine ephemeral fever (Burgess and Stradbow, 1977; MacFarlane and Haig, 1955; Theodoridise and Coetzer, 1977).

The occurrence of pulmonary emphysema might be attributed to the accumulation of exudates with the presence of cellular debris within the bronchioles which may obstruct the air pathway and induced forced respiration (Theodoridise and Coetzer, 1977). Spencer (1985) attributed the occurrence of pulmonary emphysema to obliteration and destruction of respiratory bronchioles causing air trapping and also due to inflammatory weakening of peribronchiolar alveolar walls.

Cell membrane blebbing and apoptotic bodies in BEFV-infected cells were observed by TUNEL assay and scanning electron microscopy (Chang et al., 2004). Apoptosis of structural cells in the lung might possibly be an important upstream event in the pathogenesis of chronic obstructive pulmonary disease. There was an increase in apoptotic alveolar epithelial and endothelial cells in the lung tissue. So, the net result is destruction of lung tissue and the development of emphysema (Demedts et al., 2006).

It seems possible that the partially blocked air ways combined with necrosis of the mucosa and muscular part of the bronchioles resulting in rupture of bronchioles and alveoli. The air may reach the connective tissue septae and lymphatic of the lung, and then extends subpleurally to reach the mediastinum. From there the air spreads via the thoracic inlet to the subcutaneous tissues (Theodoridise and Coetzer, 1977).

Odiawo, (1989) reported severe respiratory distress and subcutaneous emphysema that observed in 8 cattle with selenium deficiency diagnosed by estimating the glutathione peroxidase (GSHPx) activity which is a selenenzyme. Selenium is an important constituent of the enzyme glutathione peroxidase (Deneke and Fanburg, 1989). Glutathione (GSH) is an antioxidant and plays a vital role in cellular detoxification and enhancement of immune functions and acts to destroy peroxides, thereby protecting cells and membranes against oxidative damage. Glutathione peroxidase is also a constituent of blood platelets and white blood 
cells, making it an important part of the body's immune system and blood clotting mechanism (www.springboard4health.com).

Decreased GSHPx activity may result in increased synthesis of chemotactic factors for polymorphnuclear cells with releasing of their leucocytic protease (Turner et al., 1975; Ali and McDonald, 1977; Stensor and Parker, 1980; Kawaguchi et al., 1982). Leucocytic elastase was found to be responsible for induction of pulmonary emphysema in goats (Janof et al., 1977).

In the cases suffering from selenium deficiency, the blood platelets showed increased tendency to aggregate with resultant thrombus formation in pulmonary blood vessels. So selenium deficiency may be a factor involved in pathogenesis of pulmonary emphysema (Theodoridise and Coetzer, 1977). Young and Spradbrow, (1990-a) examined 44 cattle infected by intravenous injection of virulent virus and the only consistent haematological response was an increase in the number of circulating neutrophils with a concurrent decline in the number of mononuclear leucocytes. There were no detectable changes in plasma or blood volume, packed cell volume, red cell count, haemoglobin concentration, serum calcium, magnesium, phosphorus and creatinine concentrations, or aspartate aminotransferase activity.

In our study, the pathological lesions in most organs were accompanied with angiopathy of blood vessels. The latter appeared dilated and congested, some of which showed necrotic changes in the intima and the endothelial cells were desquamated within the lumen. Subintimal oedema and degeneration of tunica media could be also seen, in addition to the oedematous changes that were predominated in the lung tissue. Young and Spradbrow, (1990-b) reported increase in permeability of blood vessels associated with serosal surfaces especially synovial, pericardial, thoracic and abdominal serosae in cattle infected with bovine ephemeral fever. Yellowish turbid fluids were found in the abdominal, thoracic, and pericardial cavities. Swelling and hyperplasia of the endothelial cells, pericyte hyperplasia, fibrinoid necrosis of the small arteries and perivascular hyperplasia with occasional thrombosis of vessels in muscles were detected. Endocarditic and pleuritis were also seen. BEF virus may be directly chemotactic to neutrophils. Phagocytosis of the virus may result in neutrophil degranulation and release of vasoactive amines which induce vascular permeability

In the present study, immunohistochemically, the virus could be demonstrated within leucocytes in the lungs and lymphoid tissues of the dead animals. Using a direct fluorescent antibody technique, (Young and Spradbrow, 1985) found that BEF virus antigen was identified in synovial, pericardial, thoracic and abdominal fluids, in synovial membranes and epicardium. In synovial membranes and epicardium, specific fluorescence was observed in two cell types, mesothelial cells and neutrophils. In the fluids, fluorescence was restricted to neutrophils. Elimination of circulating neutrophils in cattle infected with BEF virus resulted in vireamia without development of clinical disease (Young and Spradbrow, 1980). Specific fluorescence, indicating the presence of BEF viral antigen, could be detected at the time of peak clinical response in individual cells in the lungs, spleen and lymph nodes as well as neutrophils. Before and after the peak fever some fluorescence was seen in cells which appeared to be reticular cells in the lymph nodes. Viral isolation in mice could be made from blood, lungs, spleen and lymph nodes over a period of no more than 3 days. It is postulated that viral growth takes place mainly in the reticuloendothelial cells in the lungs, spleen and lymph nodes and not in vascular endothelium or lymphoid cells (Young and Spradbrow, 1977). Using real-time PCR assay, the bovine ephemeral fever virus was detected in the cow blood (Stram et al., 2005).

\section{Acknowledgement}

Great thanks to Prof. Salah Deeb Ali for thorough revision of the manuscript.

\section{References}

Ali, M. and McDonald, J. W. D. (1977): Effect of sulfinpyrazone on platelet prostaglandin synthesis and platelet release of Serotonin. J. of Lab. and Clinic. Med., 89:868-875.

Abd Elghaffar, S. Kh.; Sayed, A. S. and Abd ElRahman, A. A. (2002): An Outbreak of Bovine Ephemeral Fever (BEF) At Assiut Governorate: Pathological Study. Egypt. J. Comp. Clinic. Path., 15(2): 230- 246.

Bancroft, J. D. and Stevens, A. (1996): Theory and Practice of Histological Techniques Churchill Livingstone, New York. $6^{\text {th }}$ Ed.

Burgess, G. and Spradbrow, P. B. (1977): Studies on the pathogenesis of bovine ephemeral fever. Aust. Vet. J., 53: 363-368.

Chang, C. J.; Shih, W.; Yu, F. L.; Liao, M. H. and Liu, H. J. (2004): Apoptosis induced by bovine ephemeral fever virus. J. Virol. Meth, 122(15) : 165-170.

Demedts, I. K. ; Demoor, T. ; racke, K.; Joos, G. and 
Brusselle, G. G. (2006): Role of apoptosis in the pathogenesis of COPD and pulmonary emphysema. Resp. Res., 7:53

Deneke S. M. and Fanburg, B. L. (1989): Regulation of cellular glutathione. Am. J. Physiol., 257(4 Pt 1):L163-73

Janof, A.; Sloan, B.; Weibaune, G.; Diamiano, V.; Sandhaus, R. A.; Elias, J. and Kimbel, P. (1977): Experimental emphysema induced with purified human neutrophil: Tissue localization of the instilled protease. Am. Rev. Res. Dis., 115:461-478.

Macfarlane, I. S. and Haig, D. A. (1955): Some observations on three day stiff sickness in the Transvaal in 1954. J. South African Vet. Med. Assoc, 26:1-116.

Murphy, F. A.; Taylor, W. P.; Mims, C. A. and Whitfield, S. G. (1972): Bovine phemeral fever virus in cell culture and mice. Arch. Gesmate Virusforsch, 38: 234249

Odiawo, G.O. (1989): the relationship between selenium deficiency and the development of pulmonary and subcuatenous emphysema in bovine ephemeral fever virus infected cattle. Onderstepoor J. Vet. Res., 56:123-125.

OIE (2005): Bovine ephemeral fever, www.OIE.com

Kawaguchi, H.; Ishabashi, T. and Imai, Y. (1982): increased thromboxane B, biosynthesis in platelets. Lipids, 17:577-584.

Sayed, A. S.; Sadiek, A. H. and Ali, A. A. (2001): Bovine ephemeral fever in Assiut Governorate: Clinical, laboratory and therapeutic studies. Assiut Vet. Med. J., 44(88): 157175.

Spencer, H. (1985): Emphysema. In Pathology of the Lung, vol.1, pp.557- 594. Pergamon Press, London.

Stenson, W. F. and Parker, C.W. (1980): Monohydroxyeicostetra - eionic acid ( HETES ) induce granulation of human eutrophils. J. Immunol., 124: 2100-
2104.

Stram, Y.; Kuznetzova, L.; Levin, A.; Yadin, H. and Rubinstein-Giuni, M. (2005): A real-time RTquantative(q)PCR for the detection of bovine ephemeral fever virus. J. Virol. Method., 130(1-2):1-6.

Theodoridis, A. and Coetzer, J. A. (1979): subcutaneous and pulmonary emphysema as complication of bovine ephemeral fever. Onderstepoort J. Vet. Res., 46(3):125-127 Turner, S. R.; Tainer, J. A. and Lynn, W. S. (1975): Biogenesis of chemotactic molecules by the arachidonate lipoxygenase system of platelets. Nature, 39:680-681.

Young, P. L. and Spradbrow P. B. (1980): the role of neutrophils in bovine phemeral fever virus infection in cattle. J. Infect. Dis., 64:50-55

Young, P. L. and Spradbrow, P. B. (1985): Transmission of virus fromserosal fluids and demonestartion of the antigen in neutrophils and mesthothelial cells of cattle infected with bovine phemeral fever virus. Vet. Microbiol., 10:199-207.

Young, P. L. and Spradbrow, P. B. (1990-a): Clinical response of cattle to experimental infection with bovine ephemeral fever virus. Vet. Rec., 126,(4):86-88.

Young P. L. and Spradbrow P. B. (1990-b): Demonstration of vascular permeability changes in cattle infected with bovine ephemeral fever virus. J. Comp. Path., 102(1):55-62.

Yeruham, I., Tyomkin, D. and Van-Ham, M. (2000): Ephemeral fever (three -day sickness) in cattle in Israel. The $24^{\text {th }}$ Ann. Israel Vet. Symp. April 17, 2000.

Yeruham, I.; Gur, Y. and Braverman, Y. (2007): Retrospective epidemiological investigation of an outbreak of bovine ephemeral fever in 1991 affecting dairy cattle herds on the Mediterranean coastal plain. Vet. J., 173 : 190193.

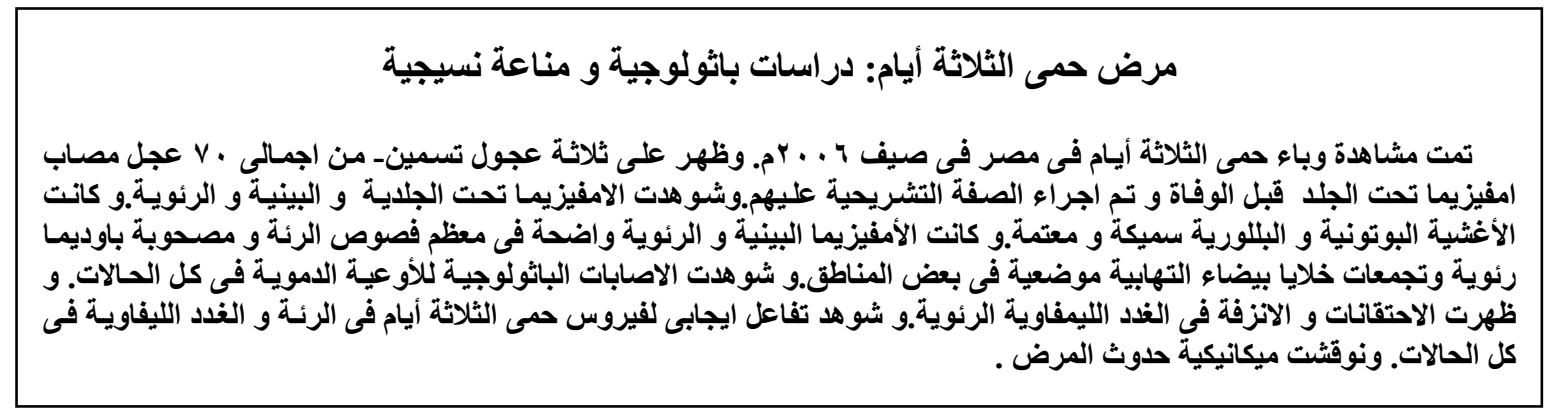

